\title{
Fatigue crack growth behaviour in the LCF regime in a shot peened steam turbine blade material
}

\author{
B.Y.He ${ }^{1, *}$, K. A. Soady ${ }^{1,2}$, B.G. Mellor ${ }^{1}$, G. Harrison ${ }^{3}$, P.A.S. Reed ${ }^{1}$ \\ ${ }^{1}$ Engineering Materials, Engineering and the Environment, University of \\ Southampton, Highfield, Southampton, SO17 1BJ, UK
}

${ }^{2}$ Now at: E.ON Technologies (Ratcliffe) Limited, Technology Centre, Ratcliffeon-Soar, Nottingham, NG11 0EE, UK

${ }^{3}$ Materials Science Centre, University of Manchester, Oxford Road, Manchester M13 9PL, UK

* Corresponding author. Tel.: +44 2380 599450; fax: +44 2380593016.

E-mail address: Binyan.he@ soton.ac.uk (B.Y.He)

\begin{abstract}
In this study, short fatigue crack initiation and early growth behaviour under low cycle fatigue conditions was investigated in a shot peened low pressure steam turbine blade material. Four different surface conditions of notched samples have been considered: polished, ground, T0 (industry applied shot peened process) and T1 (a less intense shot peened process). Fatigue crack aspect ratio $(a / c)$ evolution in the early stages of crack growth in polished and shot peened cases was found to be quite different: the former was more microstructure dependent (e.g. stringer initiation) while the crack morphology in the shot peened cases was more related to the shot peening process (i.e. surface roughness, position with respect to the compressive stress and strain hardening profiles). Under similar strain range conditions, the beneficial effect of shot peening (in the T0 condition) was retained even at a high strain level $\left(\Delta \varepsilon_{11}=0.68 \%\right), \mathrm{N}_{\mathrm{f}, \text { ground }}<\mathrm{N}_{\mathrm{f}, \mathrm{T} 1}<\mathrm{N}_{\mathrm{f} \text {, polished }}<\mathrm{N}_{\mathrm{f} \text {, T0 }}$. The $a / c$ evolution effects were incorporated in $K$-evaluations and used in calculating $d a / d N$ from surface replica data. Apparent residual stress (based on crack driving force $\Delta K$ difference) was applied to describe the benefit of shot peening and was seen to extend significantly below the measured residual stress profile, indicating the importance of the strain hardening layer and stress redistribution effects during crack growth.
\end{abstract}


Key words: fatigue crack initiation and propagation; low cycle fatigue (LCF); shot peening; residual stress and strain hardening; evolution of crack aspect ratio

\section{Introduction}

Shot peening is one of the most effective surface engineering approaches to improve fatigue resistance, and has been widely applied in a range of components, such as industrial steam turbine components (in the severe stress concentration areas). The shot peening process, as detailed elsewhere [1-3], produces inhomogeneous plastic deformation in the near surface layer which induces not only residual stress but also an increase in hardness, surface roughness, dislocation density, and also surface defects. The shot peening process is typically controlled by measuring intensity and coverage. The intensity of shot peening can be characterized by an Almen type gauge, which is a thin strip of SAE1070 designated as "A", "N" and "C" type which differ in thickness but have the same width and length; while coverage is defined as the ratio of the area covered by peening indentations to the overall treated specimen surface and is expressed as a percentage.

Many investigations have focussed on the effect of shot peening on fatigue behaviour in different material systems such as steel, $\mathrm{Al}$ and Ti alloys [4-8]. The rough surface induced is generally considered to be detrimental to fatigue resistance [4], while both the residual stress and strain hardening profiles at, and just below, the surface are considered to improve fatigue resistance $[9,10]$. The benefit of shot peening in the high cycle fatigue regime is well documented [ 9 , $11,12]$, however, in the low cycle fatigue regime, this benefit is more service condition dependent and more complex to assess, especially when it comes to residual stress relaxation or strain hardening changes during the fatigue process.

Recent reviews $[13,14]$ have detailed at some length the effects of the shot peening process (surface roughness, plastic deformation as well as residual stress) on fatigue behaviour as well as how the magnitude of these effects can be determined both experimentally and numerically. Although there has been substantial investigation into the effect of shot peening on the fatigue life of different material systems, systematic research on fatigue crack initiation and propagation behaviour (especially when operating in the LCF regime) in a notch stress field has not yet been fully explored. Whilst a few studies have tried to investigate the effect of the near surface layer induced by shot peening, 
generally only the total fatigue life has been focused upon, not the specific evolution of fatigue crack initiation or early crack propagation behaviour. The present study is an extended study building upon previous researches [15-17], aiming to understand the micromechanisms by which the crack first initiates in and then propagates through the shot peened affected layers.

\section{Materials and Experimental Method}

The material used in the present study is FV448, a ferritic heat resistant steel, which is a representative $9-12 \% \mathrm{Cr}$ steel used in low pressure steam turbine blades. This barstock material has been austenitised at $1150{ }^{\circ} \mathrm{C}$, oil quenched, and then tempered at $650^{\circ} \mathrm{C}$. The microstructure (as shown in Figure 1) and composition of this material is fully detailed in [17]. Although there is no apparent difference in microstructure [16] after the rolling process, the yield strength in the longitudinal direction is somewhat higher than that in the transverse direction, as shown in Figure 2, the $0.2 \%$ proof stress, $\sigma_{0.2}$, in the longitudinal direction decreases from $858 \mathrm{MPa}$ to $806 \mathrm{MPa}$ in the transverse direction. Oxide stringers (alumina and $\mathrm{MnS}$ ) were visible in the L-T and L-S faces running along the longitudinal direction parallel to the longitudinal axis of the original extruded bar stock, as clearly illustrated in Figure 3, this is similar to reports of another $12 \% \mathrm{Cr}$ steel FV566 [18, 19].

Samples to be shot peened were all ground to an initial surface roughness $R a$ of $<0.8 \mu \mathrm{m}$ before shot peening. Therefore, this ground surface condition with grinding marks, as well as a polished surface (where the grinding marks had been polished to a finish $\pm 1 \mu \mathrm{m}$ ) act as baseline tests for comparison with the two shot peened conditions investigated. Figure 4 shows the four different surface conditions under investigation: polished, ground, T0 and T1 shot peened cases, where T0 (MI230R 13A $200 \%$, here 230R refers to the shot size and hardness, $13 \mathrm{~A}$ is intensity and $200 \%$ represents the coverage) is applied industrially to steam turbine blades and T1 (MI110R 4A 200\%) is a lighter shot peening process [15]. The surface conditions of these four different cases were characterized by both an Alicona Infinite Focus 3D optical Microscope and a Taylor Hobson Form Talysurf 120L stylus profilometer.

The residual stress was determined by the $\sin ^{2} \psi$ method on a Proto iXRD system with a Cr-Ka beam of wavelength $2.291 \AA$ in the University of 
Manchester. The residual stress profiles along the depth direction were characterized by combining the XRD method with incremental layer removal by the electropolishing method which was detailed in [15] (electrolyte $8 \%$ (by volume) of $60 \%$ perchloric acid solution mixed in solution with $92 \%$ (by volume) of glacial acetic acid).

The fatigue crack behaviour was evaluated by three point bend tests at ambient temperature with a sinusoidal waveform and frequency of $20 \mathrm{~Hz}$ on a servo hydraulic Instron 8502 machine. To simulate the stress concentration feature in the steam turbine, the fatigue samples contain a U-notch that provides a stress concentration factor $\sim 1.6$ (which has been calculated using an elastic finite element analysis). This U-notched fatigue sample as well as the relevant $\mathrm{S} / \mathrm{N}$ data has been reported elsewhere [15, 17], as reproduced in Figure 5. Although the fatigue test was under load control with a load ratio of 0.1 , the true strain range experienced at the notch root was simulated by an elastic plastic finite element model. In the present study, crack initiation and propagation behavior were investigated under the same local strain range conditions. The true strain in the sample loading direction $\left(\Delta \varepsilon_{11}\right)$ was $0.68 \%$. The effect of any modifications to material behavior induced by surface processing, such as surface work hardening, was neglected in this calculation. This allowed a representative comparison to be drawn between the samples tested under different surface conditions.

Interrupted fatigue tests were carried out to evaluate the evolution of crack aspect ratio. Fatigue tests were interrupted at about $65 \sim 75 \%$ of the estimated fatigue life (based on the $\mathrm{S} / \mathrm{N}$ curve); the samples were then removed from the test apparatus and oxidized in an furnace at $600^{\circ} \mathrm{C}$ for 2 hours. After that, they were kept in liquid nitrogen for up to 10 minutes to allow samples to cool down thoroughly to below the ductile to brittle transition temperature. These cooled samples were then broken open with a hammer manually and the fracture surfaces were allowed to warm up to ambient temperature in acetone. The interrupted fatigue test with subsequent heat tinting process allows the evolution of crack shape in the depth of the sample to be assessed, since the fatigue crack region after heat tinting is clearly different from the subsequent brittle fracture area.

In addition, a silicone replica technique was used during fatigue testing at differing numbers of cycles to monitor crack initiation and short crack growth behavior in polished, ground, T0 and T1 shot peened cases. Crack length 
measurement from replication as well as the crack growth rate assessments are extensively described in [17].

Stress intensity factor (SIF) $K$ calculations in the present study were based on Scott and Thorpe's review paper of semi-elliptical cracks [20]. The fatigue crack was assumed to be a semi-elliptical crack in a finite thickness plate under a bending condition.

\section{Results}

A comparison of surface roughness obtained by both optical and tactile line measurement techniques for each surface condition is shown in Figure 6. In each case, surface roughness $R a$ (or $R z$ ) in line profile measurement are comparable in both the optical and contact approach. However, area roughness $S a$ (the arithmetic average of the 3D roughness) and $S z$ (maximum height of surface roughness) in all these four cases are apparently higher than $R a$ and $R z$ obtained by $2 \mathrm{D}$ profile measurements, respectively. In the ground case, grinding marks play an important role in fatigue crack propagation behaviour [17]. Roughness $R a$ in the longitudinal direction (parallel to the grinding marks) is less than that in the transverse direction (normal to the grinding marks). In the shot peened case, $R a$ in $\mathrm{T} 0$ is $3.69 \pm 0.35 \mu \mathrm{m}$ and $1.40 \pm 0.16 \mu \mathrm{m}$ in the less intense shot peened case (T1). 3D reconstruction of the as-shot peened surface were obtained by Alicona Mex based on SEM images tilted at $-5^{\circ}, 0^{\circ}, 5^{\circ}$, as shown in Figure 7. In both the T1 and T0 cases, shot peened lips at the bottom or edges of shot peened dimples and some crack-like regions are clearly revealed. However, these defects induced by severe plastic deformation in the T0 condition appeared more frequently.

Quite a thin compressive residual stress layer $(\sim 20 \mu \mathrm{m})$ near surface can be observed in the polished condition, as can be seen in Figure 8. Residual stress obtained in the ground condition was based on measurements on the U-notched geometry, which was detailed in [15]. Tensile stress was found on the ground surface in the longitudinal direction while a compressive stress (a very thin layer, $\sim 5 \mu \mathrm{m})$ was observed in the transverse direction. In both directions, tensile residual stress increased gradually up to a maximum point ( $400 \mathrm{MPa}$ in the longitudinal direction and $\sim 250 \mathrm{MPa}$ in the transverse direction) at $\sim 20 \mu \mathrm{m}$ beneath the surface. After that, the value of tensile residual stress decayed to a 
balancing compressive stress as the depth increased. The total depth of the affected layer in the ground condition is around 100 150 $\mu \mathrm{m}$. For T1, the stress distributions in the longitudinal and transverse direction showed no significant difference: the maximum compressive stress was $-620 \mathrm{MPa}$ at $50 \mu \mathrm{m}$ depth and the total residual stress affected layer extended to about $200 \mu \mathrm{m}$ beneath the surface. For T0, the residual stress is also similar in two directions: the maximum compressive residual stress in both the longitudinal direction and the transverse direction is $\sim 600 \mathrm{MPa}$. The depths where the compressive stress reached the maximum value in both directions were all around $\sim 150 \mu \mathrm{m}$, after which the compressive stress decreased gradually to a tensile stress at $\sim 340 \mu \mathrm{m}$ depth.

There are several different methods that can be applied to evaluate the plastic strain profile, such as micro-hardness, X-ray diffraction (XRD) line broadening and electron backscatter diffraction (EBSD) local misorientation techniques. As discussed extensively in [16], the results calculated from the microhardness technique indicated a greater plastic strain depth (resulting in a deeper yield strength profile) than the other two methods. This would lead to nonconservative estimates of component remnant life under this situation. The plastic strain profiles obtained by the XRD and EBSD approaches are quite similar; however, since there are more data points in the latter approach, the calculated results are more averaged, increasing confidence in the values obtained. Hereafter, further discussion regarding the residual plastic deformation in the present investigation is based on the results from the EBSD local misorientation technique. Figure 9 illustrates the plastic deformation resulting from the shot peening process in both $\mathrm{T} 0$ and $\mathrm{T} 1$ conditions. By comparison, the industry 13A process (T0) has a higher surface strain (0.2) as well as a deeper hardening profile $(150 \mu \mathrm{m})$ than that in the less intense process (T1).

The fracture surfaces of the interrupted fatigue tests after heat tinting for polished, T0 and T1 samples are illustrated in Figure 10, Figure 11, and Figure 12 respectively. The remnant crack opening after the fatigue process allowed oxidation to occur in the fatigued regions during the heat tinting process. The distinction between the fatigue and brittle failure region was apparent under SEM observation, since the brittle fracture area is more faceted or rough, while the fatigue damage area is relatively smooth. Figure 10 (a) shows the overview of the fracture surface in the polished case after the fatigue test was interrupted 
at 18292 cycles (about $65 \sim 75 \%$ of the fatigue life based on the previously established S/N curve). As shown in Figure 10 (b) and (c), the cracks identified were still quite small and individual, since no apparent crack coalescence was observed. Figure 10 (b) was the longest crack found in this specimen, with a surface projected crack length of $700 \mu \mathrm{m}$ (measurement based on the fracture surface). Crack shapes were semi-elliptical or near semi-circular; within the central fatigue region, aluminium oxide stringers (e.g. in Figure 10 (b)) and $\mathrm{MnS}$ (e.g. in Figure 10 (c)) were revealed clearly, and are likely to be the crack initiation sites.

However, early crack behaviour in the T0 shot peening condition was quite different, as shown in Figure 11. This was probably due to the complex surface condition associated with local plastic deformation as well as the residual stress distribution. The fatigue process was interrupted at 36163 cycles $(60 \sim 70 \%$ of the established fatigue life). Fatigue crack shapes were very shallow; ratchet marks in the fatigue region indicate crack coalescence has already occurred at this fatigue stage, and also there were several crack initiation sites, but these were not from inclusions. However, in the less intense shot peening process (T1), early fatigue crack initiation and propagation behaviour exhibits the features of both the polished (baseline) and T0 case, as evidenced in Figure 12 (a) and (b).

Figure 13(a) illustrates the difference between the real surface crack length $2 c$ and the projected surface crack length $2 c_{\text {project }}$. In the present study, the crack length, $2 c_{\text {project, }}$ can be measured from the fracture surface after the interrupted fatigue test. Crack morphology during the fatigue process was not only dependent on microstructure, but also varied with load/stress condition. One approach to obtain crack aspect ratio $a / c$ is to measure half surface crack length $c_{\text {project }}$ and crack depth $a$ at the deepest position directly. However, since the crack shape was not regular (as shown in Figure 13(b)) this definition of $a / c$ was not considered sufficiently representative. If all these cracks are considered to be semi-elliptical in the present investigation, then crack aspect ratio $a / c$ can be derived more systematically and consistently from measured surface crack length $2 c_{\text {project }}$ and the approximation of an equivalent semi-ellipse with this value of $c_{\text {project }}$, based on the total measured fatigue area $A$. The variation of aspect ratio $(a / c)$ with surface crack length $2 c_{\text {project }}$ as well as the nominal crack depth $a$ in both the polished notch and shot peened samples are illustrated in Figure 14 (a) and (b), respectively. 
Generally speaking, crack aspect ratio in the baseline test was around $\sim 1$, higher than observed in the T0 shot peened case, at longer crack lengths the $a / c$ ratio for the baseline condition tended to a value of 0.8. In terms of the baseline condition, for shorter cracks, $a / c$ tends to be slightly higher, for example, the shortest crack identified in this case is $117 \mu \mathrm{m}$ in length with an aspect ratio $a / c$ of 1.27 , whereas it is only 0.94 for the longest crack $(711 \mu \mathrm{m}$ in length, as illustrated in Figure 10(b)). Thus it appears that in the early stages of crack growth the crack length in the depth direction is longer than the projected half surface crack length, indicating that the crack propagated faster in the depth direction than along the surface. It is thought that the effect of the initiation process via cracking of brittle, vertically aligned stringers in the microstructure produces an initially higher aspect ratio at smaller crack sizes.

Under the effect of shot peening, however, the crack aspect ratio was initially very small, indicating a shallow crack shape. The aspect ratio tended to increase gradually as the surface crack length increased. After the aspect ratio reached its maximum value $(a / c=0.8)$, it decreased somewhat with increase of the surface crack length, this is thought to be due to frequent crack coalescence. The effect of shot peening on aspect ratio can be seen more clearly if $a / c$ is plotted against crack depth, as shown in Figure 14 (b). The depth where the aspect ratio reaches the maximum value of $a / c$ was $\sim 120-150 \mu \mathrm{m}$, similar to the position of the maximum compressive residual stress $(\sim 150 \mu \mathrm{m}$, as shown in Figure 8) and/or the depth of the shot peened plastic deformation layer $(\sim 160 \mu \mathrm{m}$, as can be seen in Figure 9) for the T0 shot peened condition. This shallow crack shape indicated the crack growth rate in the depth direction (i.e. growing into an increasing compressive residual stress field) was actually slower than the growth rate at the surface.

In the less intense shot peening case (T1), both microstructure and the shot peening effect played an important role in fatigue crack shape evolution. Crack morphology aspect ratio evolution shows features of both the polished (baseline) and T0 shot peened cases and distinction between these two regimes can be visualized in Figure 14 (a): where it can be seen that some of these aspect ratios fall into the data cluster for the polished condition while the others fit well with aspect ratios of the $\mathrm{T} 0$ condition.

Figure 5 shows that under similar applied strain range conditions, the fatigue life of the ground, T1 and polished cases are quite similar, while the T0 case still shows significant benefit from the shot peening process, even in this low 
cycle fatigue regime. The variations in $c$ at different number of cycles in polished, ground, T0 and T1 condition are shown in Figure 15 (a), (b), (c) and (d), respectively. What should be noted here is that all the fatigue cracks studied in the present research are all dominant cracks which coalesced and led to the final failure. To make a clear comparison between the different surface conditions, all these data points in (a)(b)(c)(d) are combined together as shown in Figure 15 (e). Half surface crack length $c$ at different fatigue life ratios in all these four conditions are illustrated in Figure 15 (f). Fatigue cracks in the baseline condition (polished and ground) appeared at around 50\% of fatigue life and after that these cracks developed at a constant rate and accelerated near the end of fatigue life, when the main cracks coalesced, leading to failure. Although the cracks in the $\mathrm{T} 1$ case were also clearly picked up at $50 \%$ of fatigue life, crack coalescence in the later fatigue stages was obvious. However, some of the cracks observed in the $\mathrm{T} 0$ case in the very early stages of fatigue life were preexisting (for example, one of the initiating cracks was $51 \mu \mathrm{m}$, while the other one was $242 \mu \mathrm{m}$ before any cyclic loading had been applied). This indicates that they were pre-existing on the shot peened surface and these pre-initiated cracks started to grow very slowly at $\sim 0.1 \sim 0.2$ of fatigue life but the crack lengths did not increase dramatically until $0.7 \sim 0.8$ of fatigue life, where crack coalescence occurred frequently and secondary cracks also began to grow.

Based on the number of ratchet marks on the fracture surface, crack initiation sites in the $\mathrm{T} 0$ condition were as many as 18 , while only about 11 initiation sites were observed in the polished and ground baseline cases (Figure 16). However, there are only 7 initiation sites observed in the less intense shot peening process (T1). Based on the replication studies, cracks in the early fatigue stages were very small and ratchet marks left by early stage crack coalescence were not easy to distinguish. Compared to the shot peened case, crack coalescence in the ground sample occurred infrequently even near the end of fatigue life, partly because there were significantly less initiation sites during the fatigue process.

\section{Discussion}

Material microstructure played an important role in fatigue crack initiation and propagation. Alumina and $\mathrm{MnS}$ are two of the most common non-metallic inclusions present in steel, and these stringers can be clearly identified in the present study. Since in this study, the fracture surface (crack plane) is actually 
parallel to the longitudinal direction where these stringers are distributed, in the baseline conditions, these stringers tended to be favoured crack initiation sites. The cracks initiated along the brittle aluminium oxide stringers or inclusions, which were either on the surface or slightly beneath the surface. Since the stringers are in the longitudinally aligned direction, which is parallel to the crack depth direction, at the very early fatigue stage, those fatigue cracks initiated at stringers (or inclusions) were encouraged to propagate in the depth direction, due to the higher stress intensity around these elongated, brittle and mechanically mismatched inclusions. So the initiating inclusion position and shape will strongly affect the initial fatigue crack morphology leading to an initially larger crack aspect ratio (around 1.2). As the crack propagated, the range of stress intensity factor around the initiation sites became less dominant and the crack grew to the more expected equilibrium shape, where the stress intensity factor at both the crack surface and depth are the same.

Whilst in the less intense shot peening process (T1), the effect of these inclusions was still significant, more intense shot peening (T0) overcame the microstructure dominated initiation process as evidenced by inclusions being seldom found in the fatigue region. In this case, almost all the cracks initiated from the surface with no clear evidence of subsurface crack initiation. Furthermore, for a crack initiated from the rough shot peened surface, cracks tended to propagate along the surface direction rather than the depth direction when the crack tip process zone is within the shot peened affected zone; once it breaks through this region, crack growth in the depth direction becomes faster. This explains why the smaller cracks are shallow (low $a / c$ ) in shot peened samples.

Compared to the ground surface condition, the fatigue life is slightly longer for the polished notch surface, showing about a $12 \%$ improvement. For the T0 case, the fatigue life is almost twice that for the polished, ground, or less intense shot peened specimens under a similar applied local strain condition $\left(\Delta \varepsilon_{11}=0.68 \%\right)$. The improvement of fatigue life is due to a complex interrelation of the effect of the surface roughness induced by the shot peening process, the compressive residual stress distribution as well as the work hardened layer.

For many engineering components and structures, short fatigue crack behaviour controls the majority of total fatigue life. A number of researchers have reported that these short cracks propagate much faster than long cracks under equivalent stress intensity factor ranges $\Delta K$ [21-23]. Conventionally, small crack data 
analysis approaches employ secant or polynomial data reduction, assuming that small crack shapes are semi-circular $(a / c=1)$. However, the results of Ravichandran's study [24, 25] strongly indicate that some of these apparent characteristics of small cracks, often referred to as anomalous, are in fact partly due to the assumption that $a / c=1$. He found that allowing for the lower levels of crack closure found naturally in small cracks, and for the $a / c$ variations in $\Delta K$ calculations, the scatter in the growth data of small cracks was significantly reduced and was found to be of the same order as in large cracks. In the present study, it is also noteworthy that the crack aspect ratio varies with crack length $c$ (and, ergo, also crack depth $a$ ). The change of aspect ratio in the shot peened condition is especially obvious, varying between 0.38 and 0.83 , while it is more consistent between 0.9 and 1.2 in the polished notch condition. Therefore, it is necessary to consider the aspect ratio evolution when analysing fatigue crack initiation and propagation behaviour in terms of the crack tip stress intensity factor.

A Linear Elastic Fracture Mechanics (LEFM) calculation of $K$-equilibrium around the crack front was conducted based on Scott and Thorpe's review paper [20]. A local stress level $\left(\Delta \sigma_{11}\right)$ of $1500 \mathrm{MPa}$ in the loading direction was used in calculating the short crack $\Delta K$ levels in the notch root. This stress range was estimated using finite element modelling, implementing an isotropic hardening model based on the monotonic tensile data obtained in the direction perpendicular to rolling. Assuming a notional crack in the polished condition (not considering the shot peening effect), its crack shape area A is fixed, the crack depth $a$ at varying crack aspect ratio $a / c(a / c=0.1,0.2,0.3, \ldots, 1.8,1.9$, 2.0) can be obtained. The variation of $\Delta K_{\text {surface }}$ and $\Delta K_{\text {depth }}$ for cracks with the same fatigue area but different $a / c$ ratios is illustrated in Figure 17 (a). At low aspect ratios, the expected $K$ in the depth direction is greater than that at the surface; whilst at a high aspect ratio the expected $K$ in the surface direction is greater than that in the depth direction when $a / c$ is $0.8, \Delta K_{\text {surface }}$ and $\Delta K_{\text {depth }}$ are in equilibrium. This is consistent with the experimental crack aspect ratio evolution, where the aspect ratio ( 0.8) was achieved in both the baseline and shot peening tests once the crack had grown away from the effect of microstructural initiation and the shot peened affected layer respectively.

In fact, the equilibrium $a / c$ also varies with absolute crack size. But it is a challenge to unambiguously characterize this feature through these interrupted fatigue tests, since when the crack length $2 c$ is longer than $1000 \mu \mathrm{m}$, the fatigue 
test is in the last stages of fatigue life and crack coalescence events are happening frequently and affecting the aspect ratio measurement for differing reasons. In Figure 17(b), the characterization of the change of equilibrium $a / c$ at different surface crack lengths was based on the assumption of isolated individual cracks with different surface crack length $2 c(50,100,200,500,1000$, $2000 \mu \mathrm{m})$. When the surface crack length $2 c$ is no more than $500 \mu \mathrm{m}$, the equilibrium $a / c$ is 0.8 , as is the case in observations from the interrupted fatigue test cases. However, as the surface crack length increases, this equilibrium value decreases gradually, for example, $a / c_{\text {equilibrium }}$ is 0.75 at $1000 \mu \mathrm{m}$ while it drops to 0.52 if the surface crack length $2 c$ is $5000 \mu \mathrm{m}$. This trend is expressed as equation $g(x)$ in Figure 18 (a) and (b), which shows the evolution of crack aspect ratio in both non-peened and shot peened conditions. In the polished and ground case, the evolution of $a / c$ will be given by equation $k(x)$ when crack length $2 c \leq 2065 \mu \mathrm{m}$, while equation $g(x)$ will be applied to describe $a / c$ if the surface crack length $2 c>2065 \mu \mathrm{m}$. While for shot peening cases, equation $f(x)$ describes the trend of crack aspect ratio when $2 c \leqslant 289 \mu \mathrm{m}$ and equation $g(x)$ is the appropriate one for cracks longer than $289 \mu \mathrm{m}$.

Figure 19 (a), (b), (c) and (d) illustrates the fatigue crack growth rates $d c / d N$ (calculated by the secant method) for polished, ground, T0 and T1 notch samples plotted as a function of $\Delta K_{\text {surface. }}$ The crack tip stress intensity factor in terms of $\Delta K_{\text {surface }}$ and $\Delta K_{\text {depth }}$ discussed in this study consider the evolution of crack aspect ratio, respectively. Again, all these data points in $(a)(b)(c)(d)$ are put together for comparison, as shown in Figure 19 (e). Figure 19 (f) shows the fatigue crack growth rates $d a / d N$ as a function of $\Delta K_{\text {depth }}$ in these four conditions. Although these data are highly scattered, this exhibits typical short fatigue crack behavior. The $d c / d N$ versus $\Delta K_{\text {surface }}$ data gives a reasonable comparison of crack growth rates under similar externally imposed stress/strain states, ignoring any local effects of work hardening or compensating residual stresses. Short crack growth behaviour in both the polished and ground cases is similar. For the T0 case, almost all the data points are well below those in polished and ground cases, which indicates the intrinsic benefit of shot peening, even when the varying evolution of crack aspect ratio on $\Delta K$ is accounted for. However, the multi-mechanism controlled fatigue behaviour in the $\mathrm{T} 1$ case can be clearly identified as these data points overlap with both the baseline conditions as well as the $\mathrm{T} 0$ case. 
Despite the data still being quite scattered in terms of $d a / d N$ versus $\Delta K_{\text {depth }}$, the shot peening benefit is more obvious, even in the T1 case. At the same crack driving force $\left(\Delta K_{\text {depth }}\right), d a / d N$ in the shot peening cases is generally slower than in the baseline conditions. The fatigue crack growth rates $d a / d N$ of T0 and T1 shot peened notch samples plotted as a function of $\Delta K_{\text {depth }}$, are compared with $d a / d N$ vs $\Delta K$ data for long crack SENB tests carried out in the same material at ambient temperature, as illustrated in Figure 20 (a) and (b). If we compare the SENB long crack propagation data with these two conditions, the long crack growth rate data fits well with the polished notch and ground conditions, although exhibiting considerably less scatter. This gives some confidence in the $\Delta K$ levels calculated in the notch root and the more accurate calculation of crack aspect ratio evolution.

After shot peening, there is an induced compressive residual stress in the near surface layer. When an external cyclic stress is imposed during a fatigue test, stress superposition will occur during loading, as well as possible relief of the compressive residual stress during the fatigue process. We should note here that Soady et al. saw little or no relaxation of residual stresses at $50 \%$ of lifetime in their study [15]. As a result, the actual stress state in the surface layer arising from the applied stress and the pre-existing strain hardening and residual stress distributions, will affect fatigue crack growth behaviour in the affected surface layer. However, not only the compressive residual stress, the strain hardened layer but also the surface roughness will influence fatigue behaviour, so the slower fatigue crack propagation rate observed in the shot peened sample is actually due to the interaction of these three factors.

Based on equivalent crack driving force we can estimate the difference in $\Delta K$ for a given $d a / d N$, hence an apparent residual stress. Due to the scattered data sets, a lower and upper bound can be drawn; therefore, the corresponding lower and upper bound of the apparent residual stress can be obtained. In Figure 20 (c) and (d), the overall trends of the apparent residual stress in T0 and T1 are both quite similar to the measured residual stress, respectively - decreasing gradually with increasing depth, and at some point, after reaching the minimum point, the apparent residual stress increases, which indicates the crack driving force decreases gradually. However the minimum point of these apparent residual stresses (i.e. the most significant retardation) coincides with the depth of the shot peening plastic deformation layer as well as the maximum compressive residual stress. The lower and upper bound of the apparent residual stress 
brackets the measured ones but extends far deeper in both $\mathrm{T} 0$ and $\mathrm{T} 1$ cases. This is probably due to the additional retardation effects of the strain hardened layer, effects of stress redistribution as the cracks grow and coalescence/shielding behaviours which are not captured by this simplifying apparent residual stress assumption.

\section{Conclusions}

- Four different surface conditions in notched samples have been the focus of the present study: polished and ground (as baseline conditions), T0 (industry applied shot peened process) and T1 (less intense shot peened process). Fatigue crack aspect ratio ( $a / c)$ evolution in the early stages of crack growth in polished and shot peened cases was investigated. In the polished sample, microstructure (alumina stringers as well as $\mathrm{MnS}$ ) played an important role in early crack initiation and propagation. Initialliy, the aspect ratio for these short cracks was around 1.0 1.2, as the surface crack length $2 c$ increased, the value decreased to the equilibrium aspect ratio 0.8 . While in the T0 shot peened case, the aspect ratio was low initially and increases with increasing crack depth $a$ when $a$ $<120 \sim 150 \mu \mathrm{m}$, after which the crack aspect ratio decreased gradually (due to frequent crack coalescence). However, $a / c$ evolution in the T1 sample combines trends observed in the $\mathrm{T} 0$ and polished conditions. The shallower aspect ratio in the shot peened case has been linked to the greater difficulties encountered by the crack to grow sub-surface into the compressive residual stress and strain hardened layer compared to the polished case.

- Under the same expected strain range condition $\left(\Delta \varepsilon_{11}=0.68 \%\right)$, the ground and $\mathrm{T} 1$ shot peening case have similar fatigue life, while the polished case benefitted somewhat from the well finished surface and fatigue life improved by $\sim 12 \%$. The T0 shot peened process exhibited the best fatigue life, almost twice that of the baseline and $\mathrm{T} 1$ cases even in the LCF regime. The crack growth behaviour in polished (baseline) condition is similar to that in the ground condition, whilst crack growth rates in the shot peened case are significantly delayed while the crack grows through the expected depth of the significant compressive residual stress field/work hardened region. 
- The $a / c$ evolution effects were incorporated in $K$-evaluations and assumptions about growth in the depth direction; apparent residual stress (based on crack driving force $\Delta K$ difference assumptions) shows crack growth retardation beyond the measured region of compressive residual stress, which is probably due to the effects of the strain hardened layer, stress redistribution as the cracks grow and coalescence behaviour which are not captured by this assumption. Further work is ongoing in the group at Southampton to evaluate these effects via modelling approaches aiming to simulate these detailed experimental observations.

\section{Acknowledgements}

Financial support from China Scholarship Council, as well as E.ON Technologies (Ratcliffe) Ltd. is gratefully acknowledged. Thanks are also extended to Chao You, a student at the University of Southampton for his assistance in gathering residual stress data and to Dr Iain Paterson of E.ON Technologies (Ratcliffe) Ltd. for helpful discussions.

\section{Figures:}

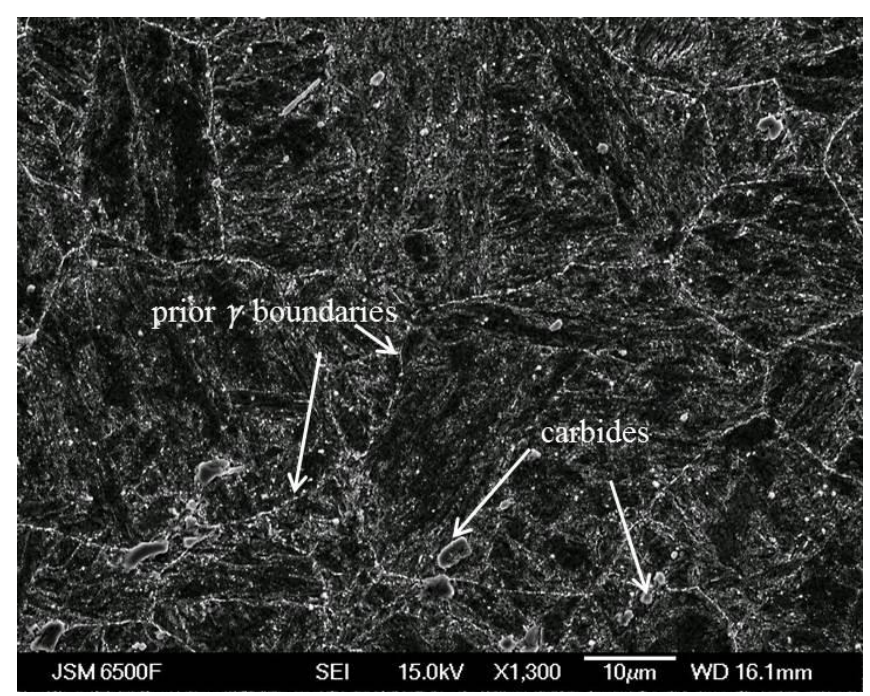

Figure 1 FEGSEM (SEI mode) micrograph of polished and etched (by Vilella's Reagent) sample revealing the microstructure of FV448 [17]. 


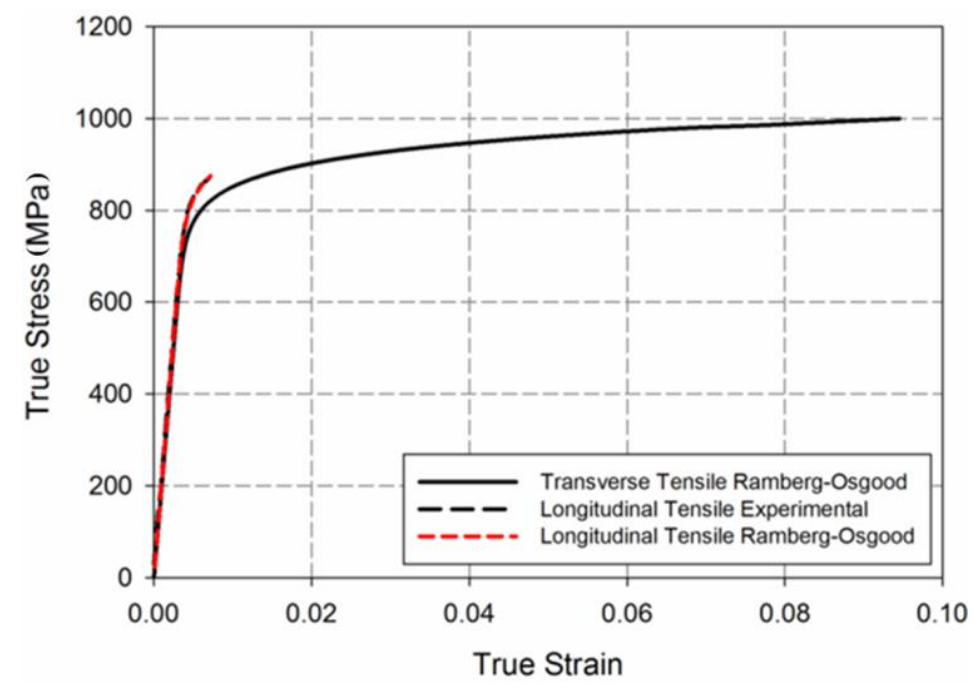

Figure 2 Comparison of tensile behaviour in the longitudinal and transverse directions.
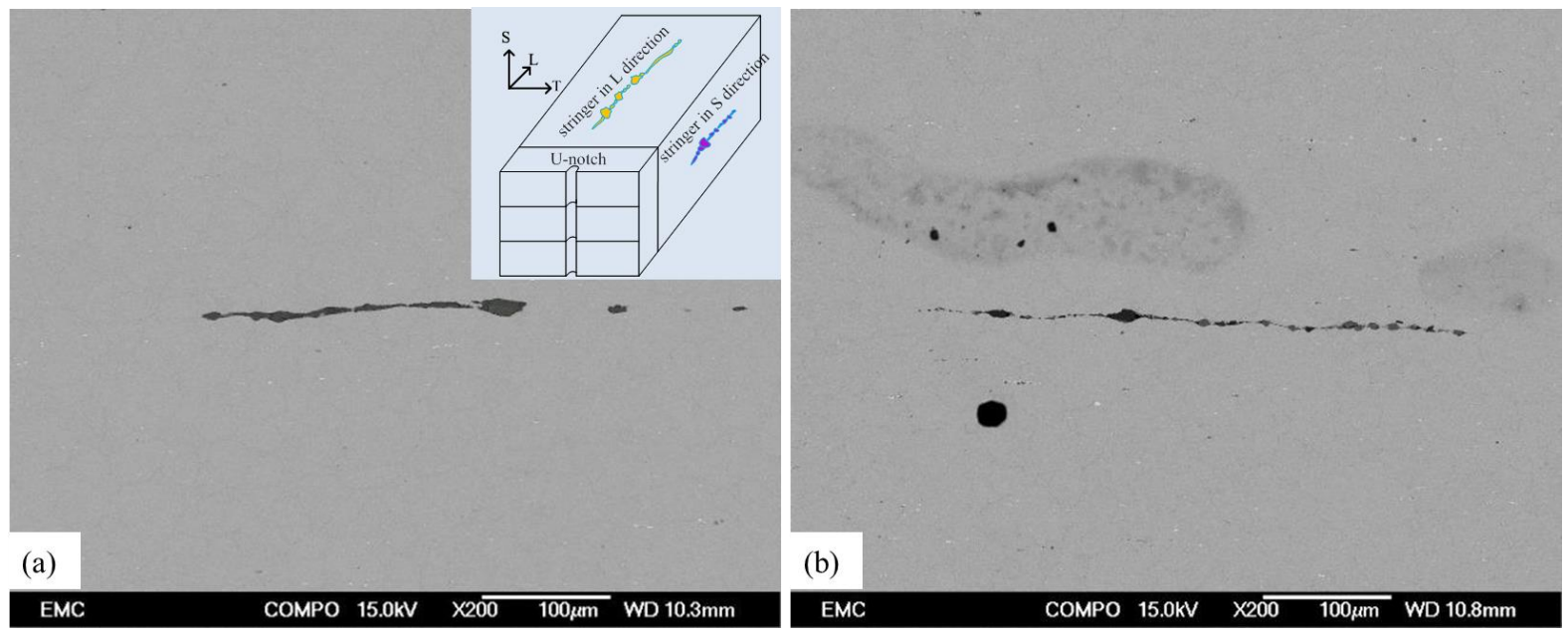

Figure 3 The schematic illustration in (a) shows the positions of the stringers in the barstock; inclusions of aluminium oxide/silicate and manganese sulphide aligned in the longitudinal direction (a) on the L-T face; (b) on the L-S face within the FV448 matrix. 

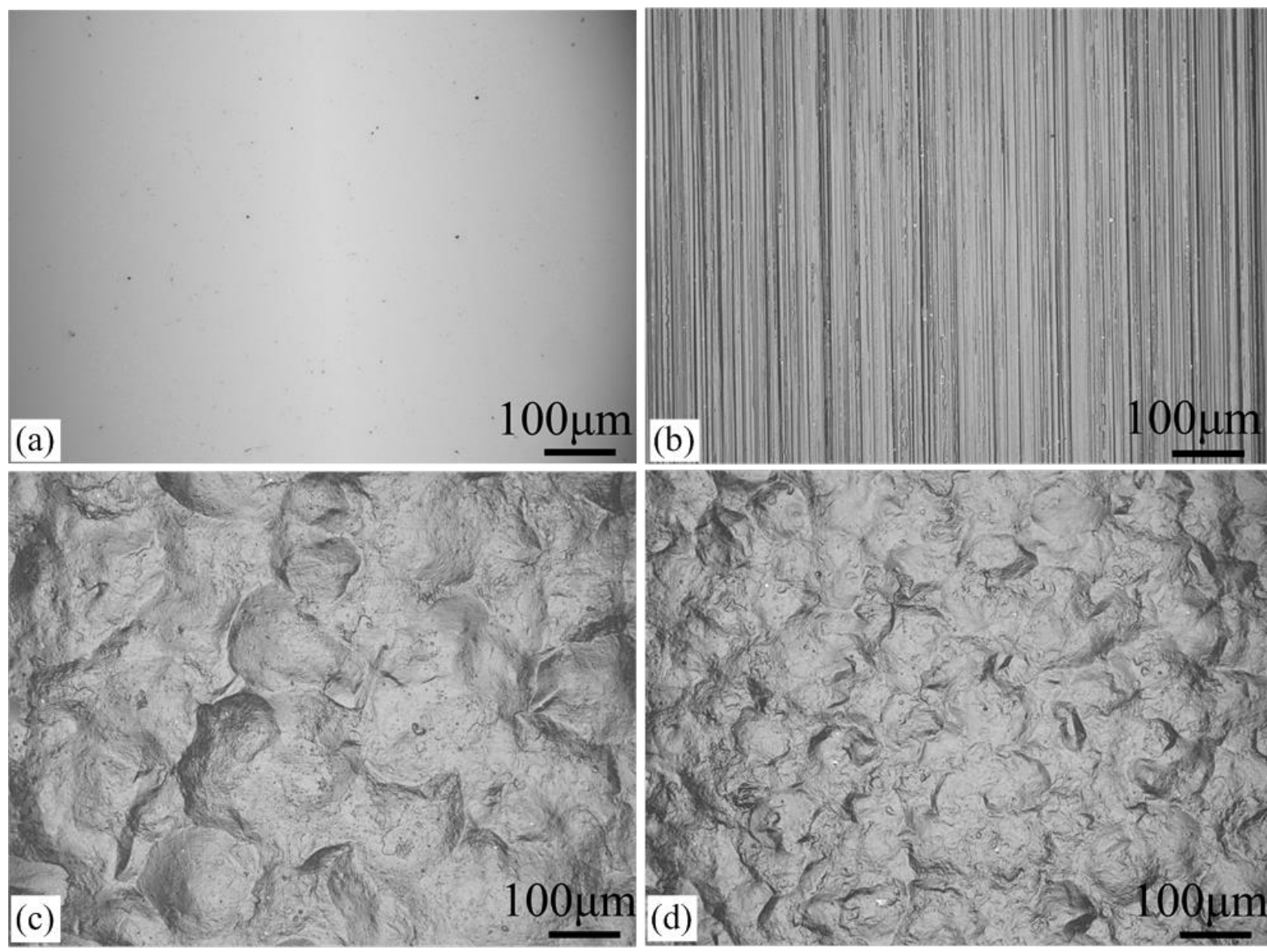

Figure 4 Optical micrographs of the four different surface conditions: (a) polished, (b) ground, (c) T0 shot peened condition and (d) T1 shot peened condition.

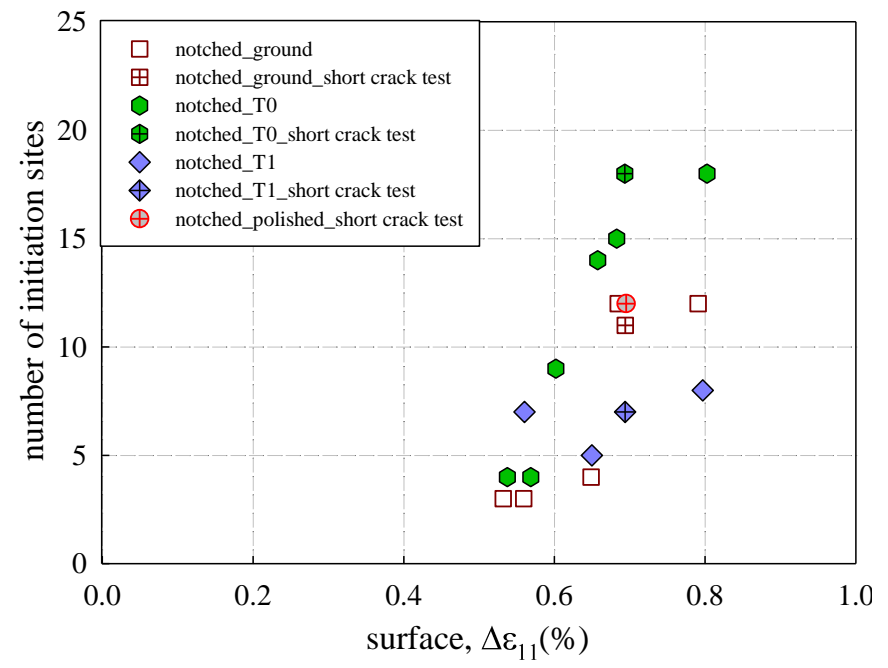

Figure $5 \Delta \varepsilon_{11}$-N curve of notched samples in ground, T0 and T1 shot peened conditions (part of data from [15]). 


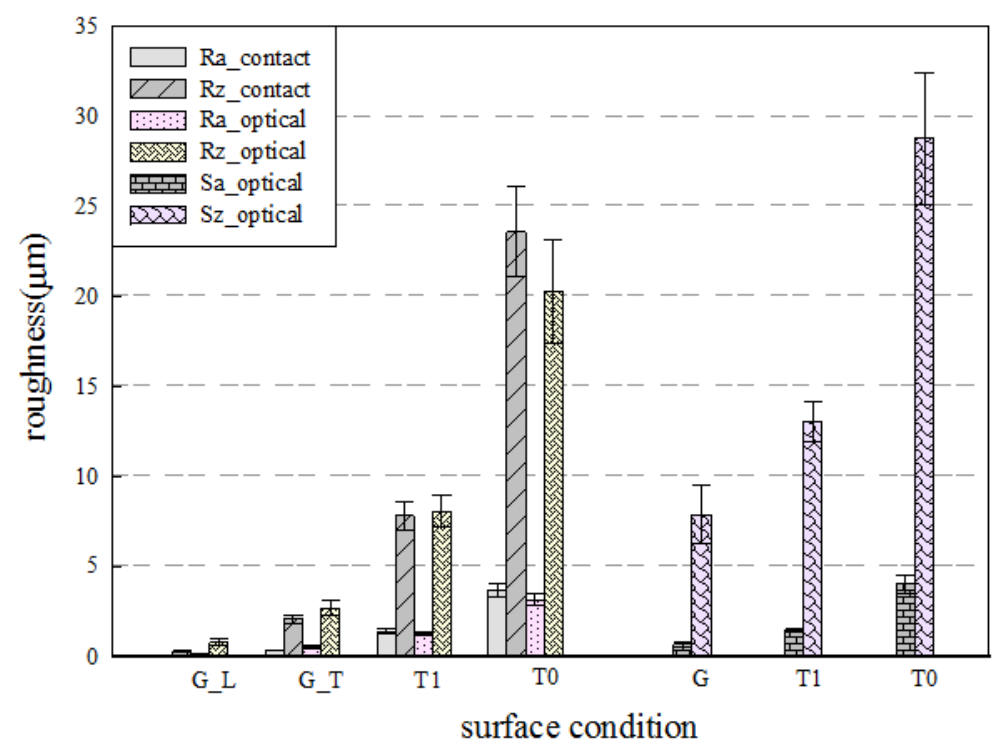

Figure 6 Comparison of surface roughness measurements for each surface condition by both contact and optical approaches.

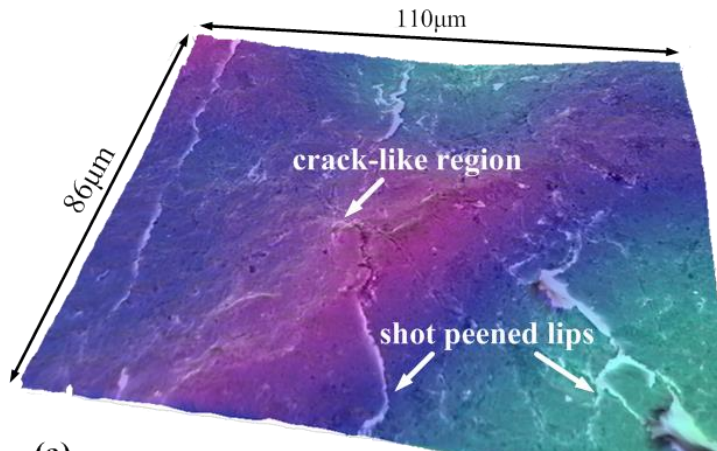

(a)

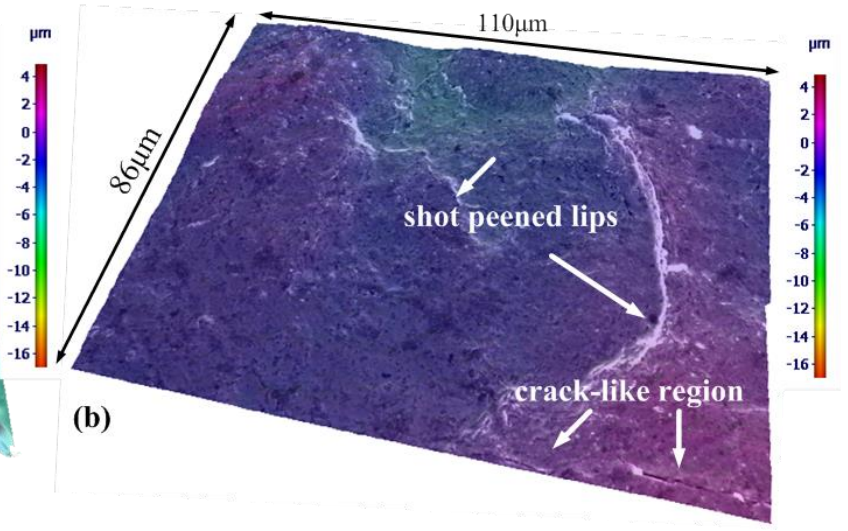

Figure 7 3D as-shot peened surface reconstruction by Alicona Mex based on SEM images tilted at $-5^{\circ}, 0^{\circ}, 5^{\circ}:$ (a) $\mathrm{T} 0$ and (b) $\mathrm{T} 1$. 


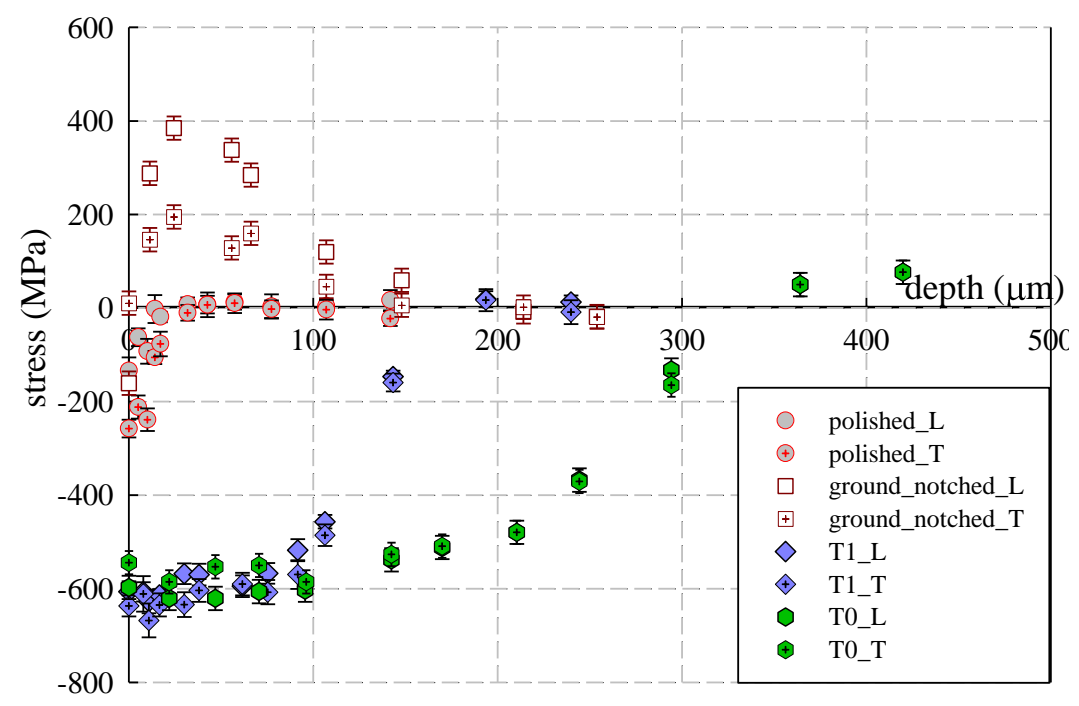

Figure 8 Residual stress distribution resulting from grinding, T0 and T1 shot peening ( $\mathrm{G}$ and T0 data taken from [15] in both longitudinal (L) and transverse (T) direction ).

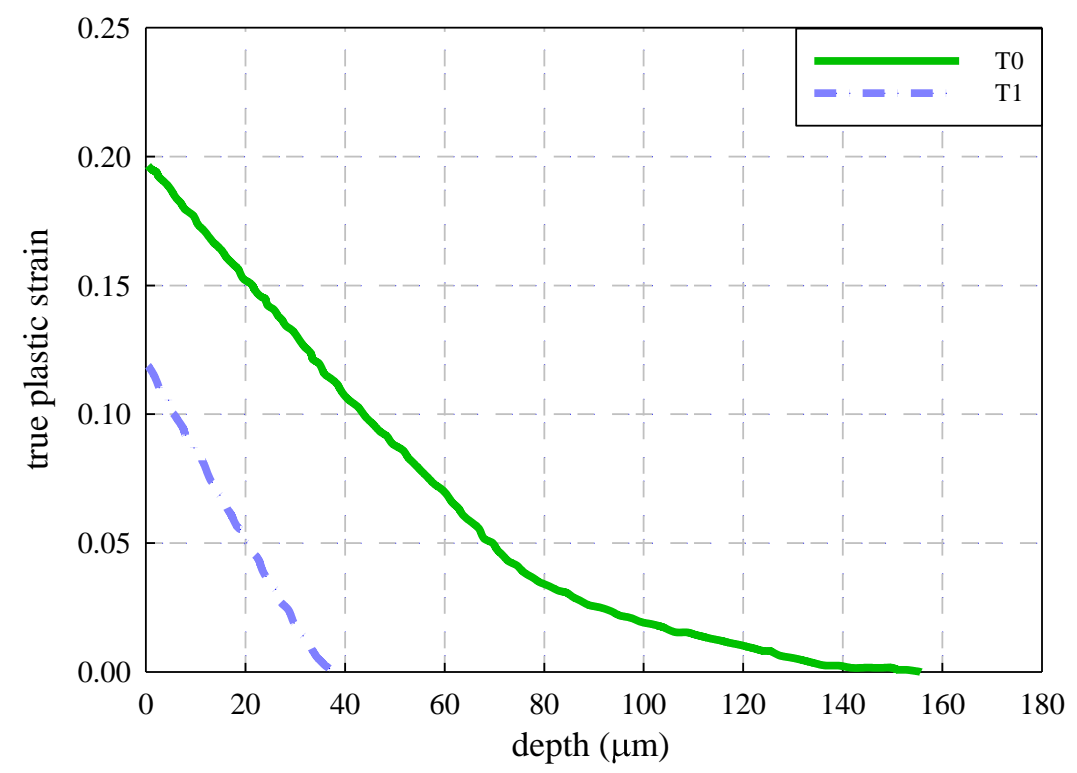

Figure 9 Comparison of strain hardening layer (by EBSD) in T0 and T1 [16]. 


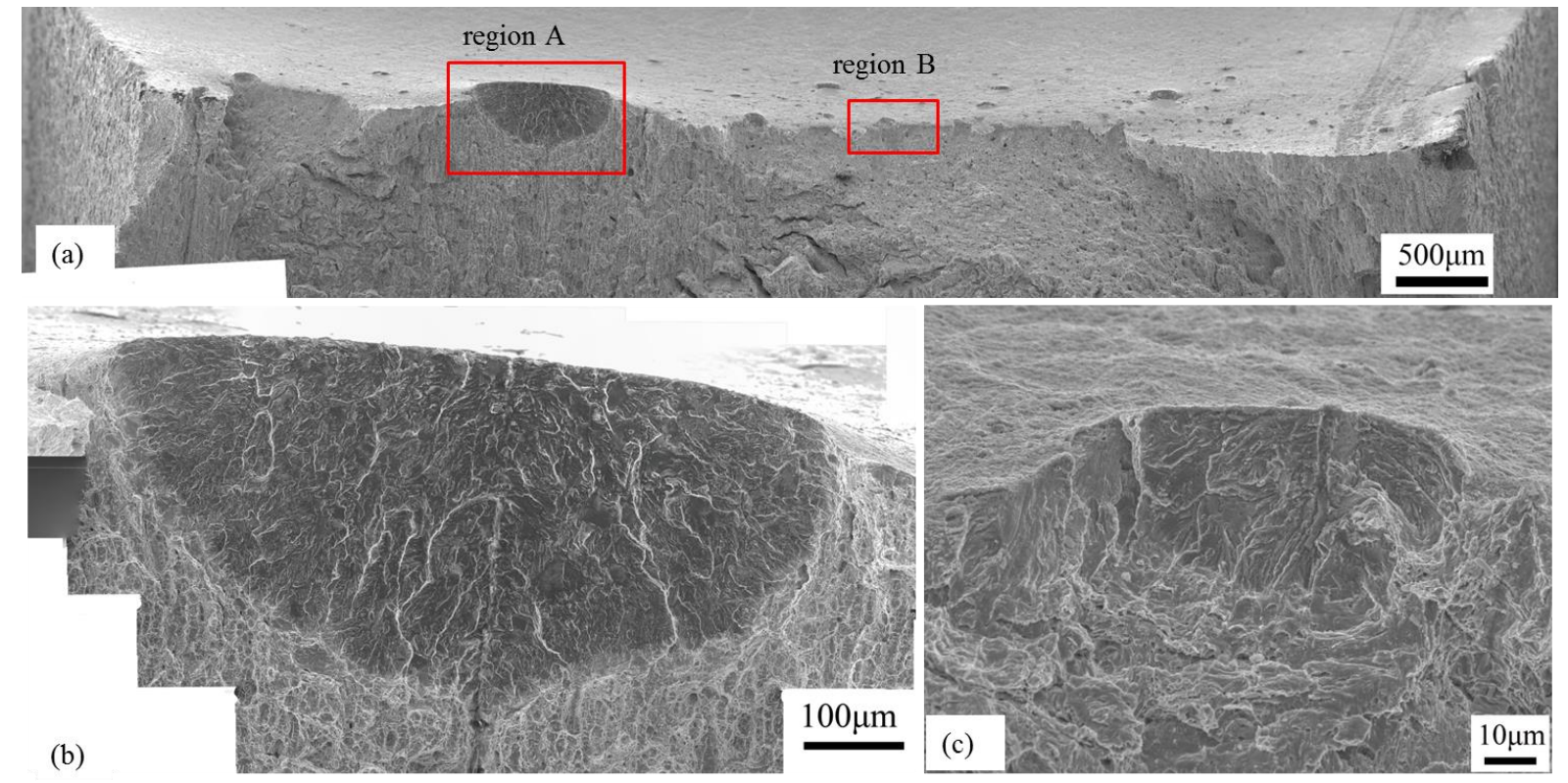

Figure 10 (a) Overview of polished case fracture surface after interrupted heat-tinted test; (b) fatigue crack region $\mathrm{A}$ and (c) fatigue crack region $\mathrm{B}$. 

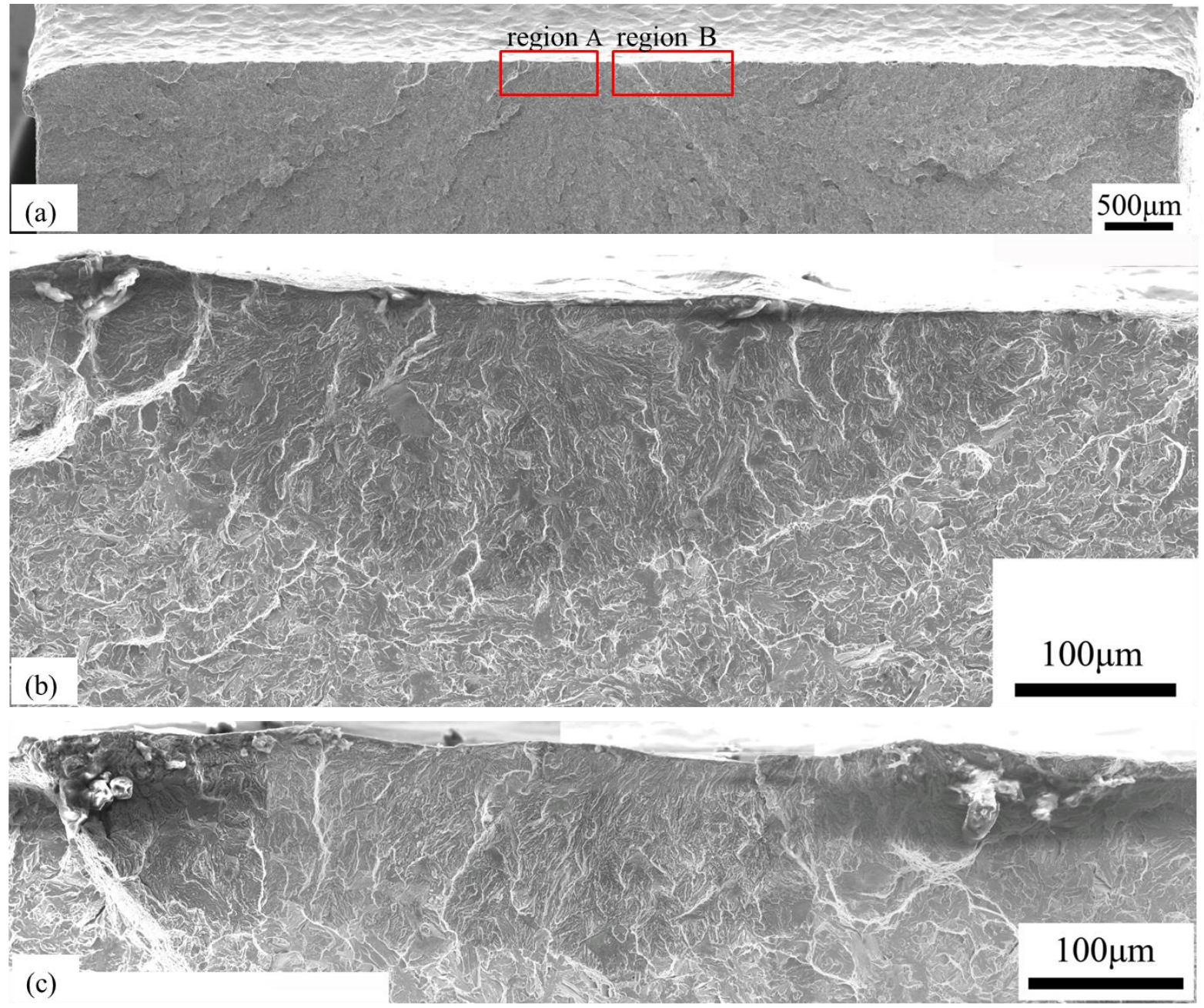

Figure 11 (a) Overview of T0 shot peened case fracture surface after interrupted heat-tinted test; (b) fatigue crack region $\mathrm{A}$ and (c) fatigue crack region $\mathrm{B}$.
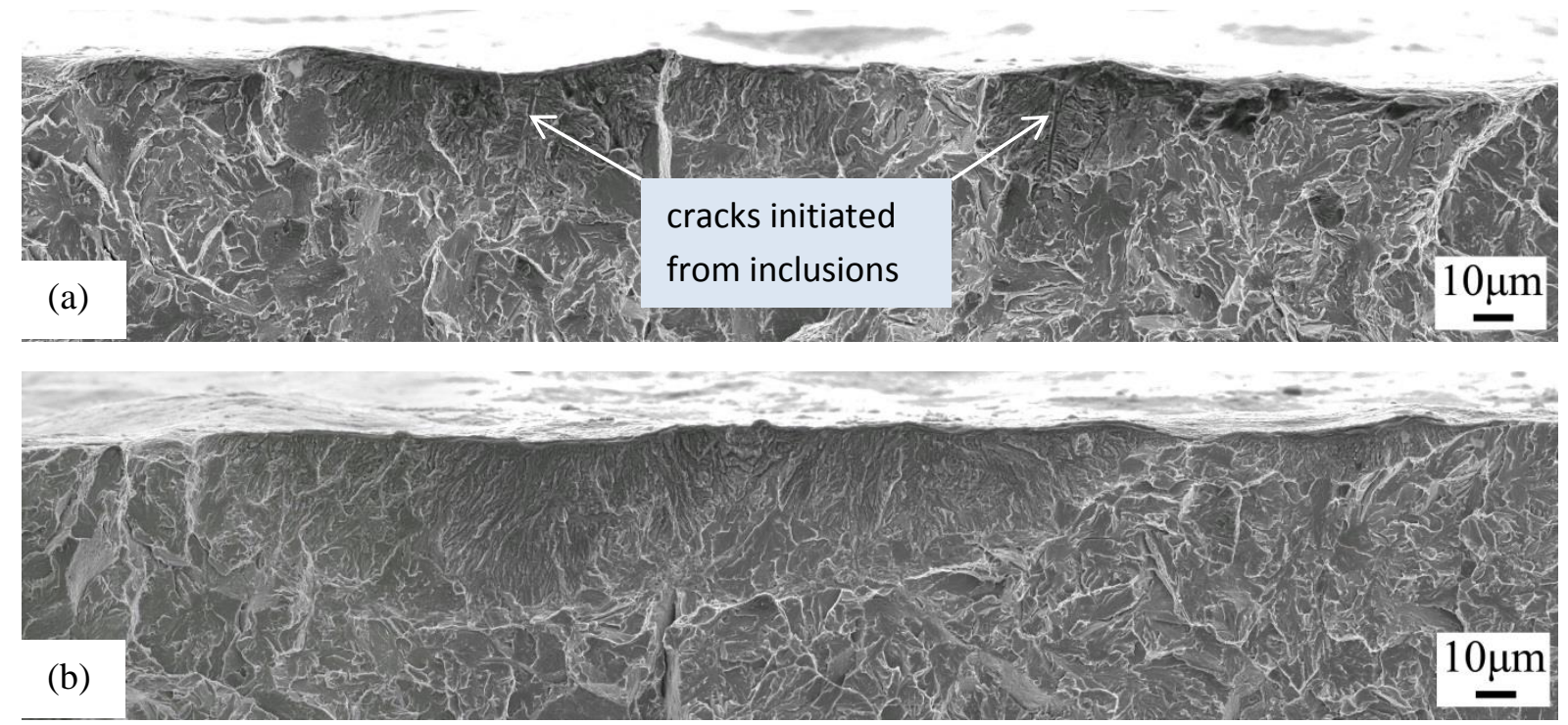

Figure 12 Fracture surface of $\mathrm{T} 1$ shot peened case after interrupted heat-tinted test: (a) fatigue cracks initiated from inclusions (b) shallow fatigue crack region. 


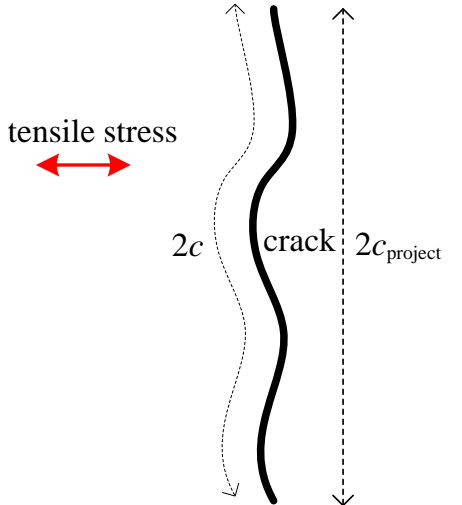

(a) tensile stress

$\otimes$

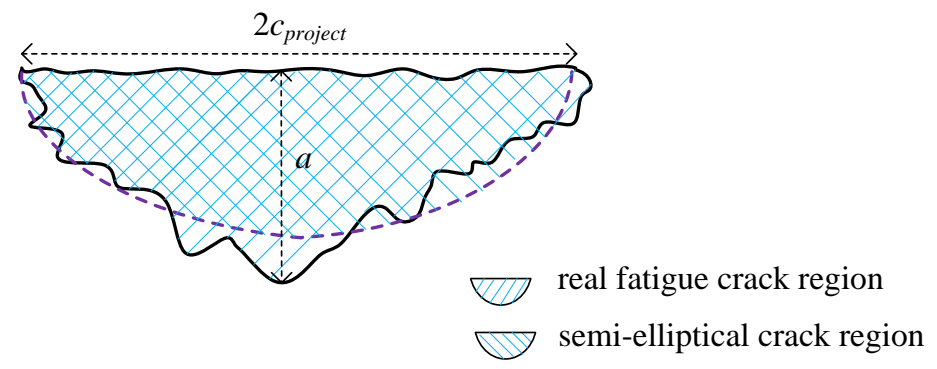

(b)

Figure 13 Schematic diagram showing (a) the difference between the real crack length $2 c$ and $2 c_{\text {project }}$; (b) crack aspect ratio $(a / c)$ calculation based on the crack morphology on the fracture surface.

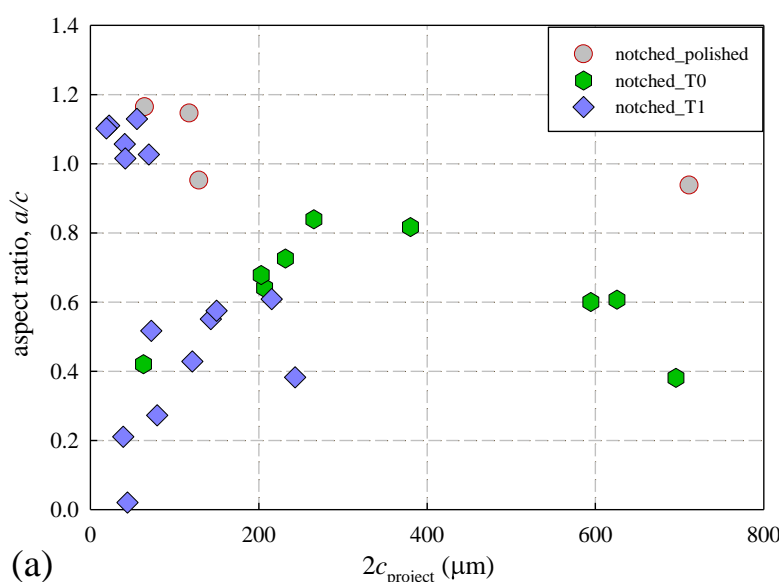

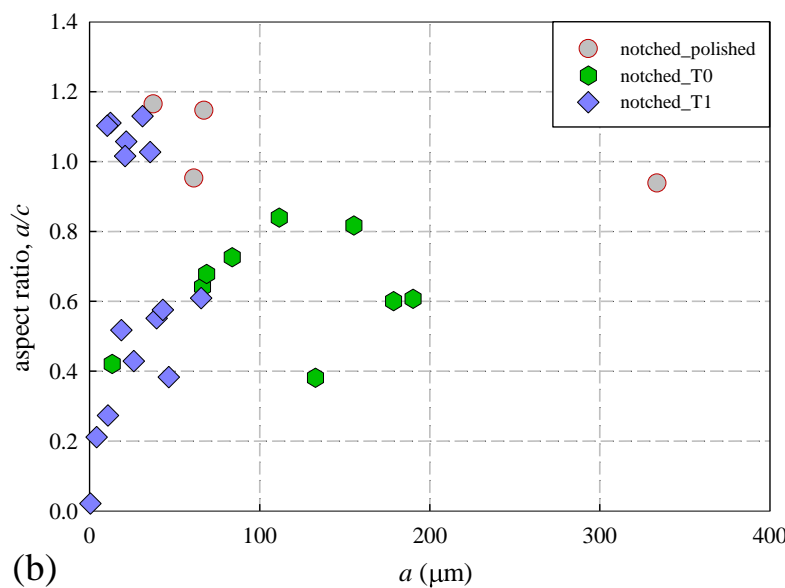

(b) $a(\mu \mathrm{m})$

Figure 14 Crack aspect ratio $a / c$ based on the fatigue crack morphology on fracture surface in T0 and T1: (a) $a / c$ at various crack lengths $2 c_{\text {project }}$; (b) $a / c$ changes with crack depth $a$.
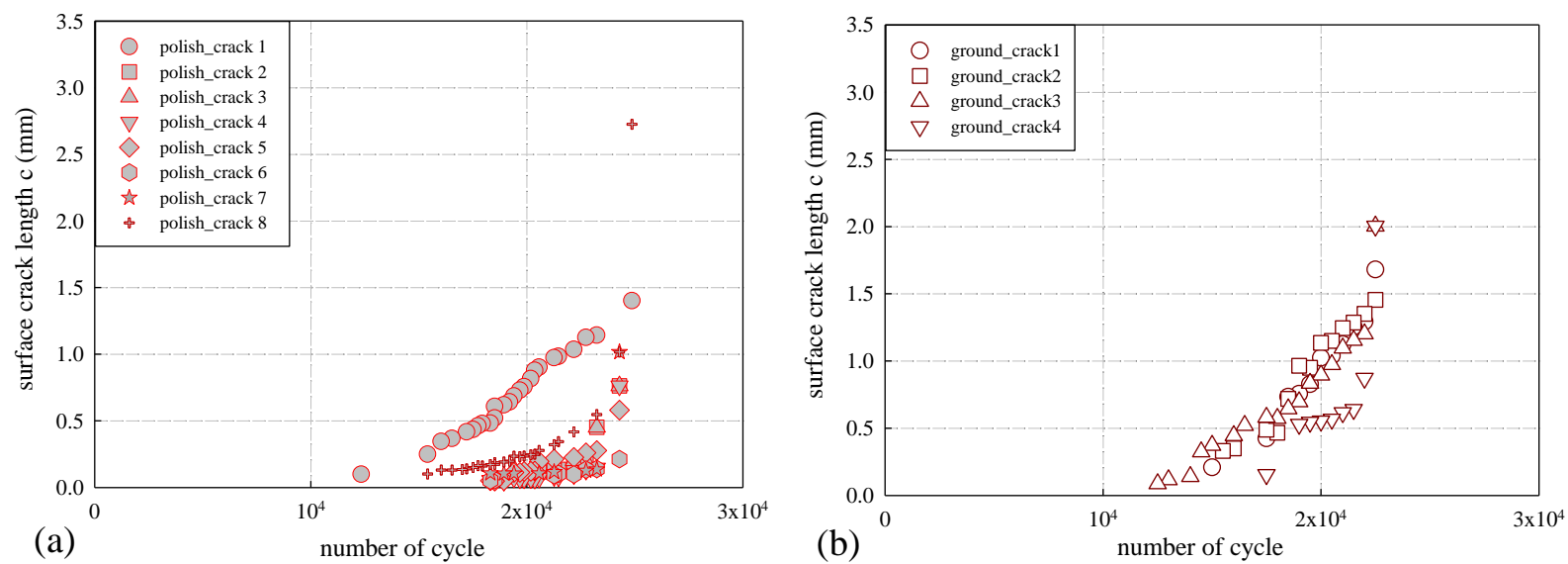

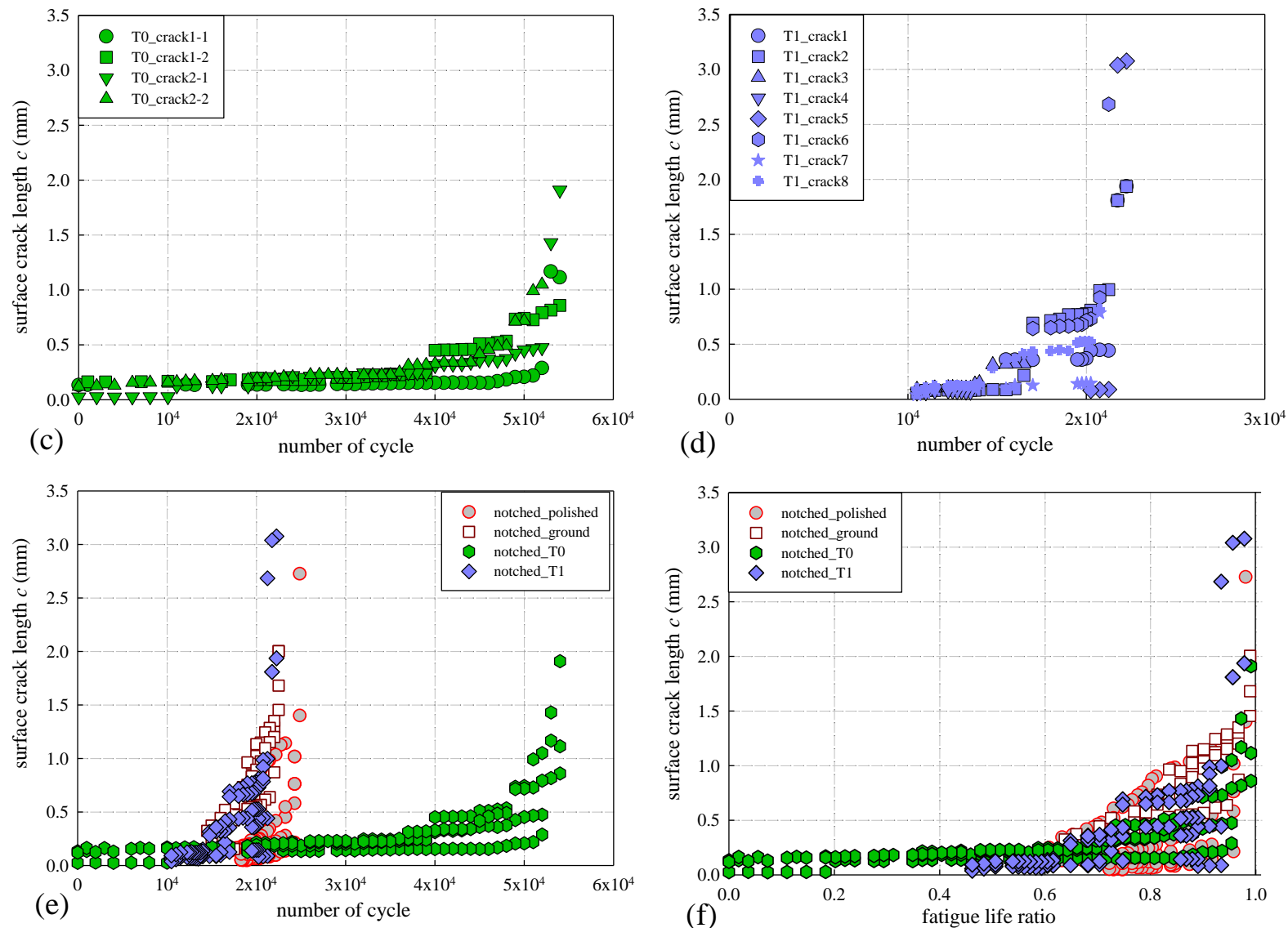

Figure 15 Half surface crack length $\mathrm{c}$ at different cycles of fatigue life in (a) polished surface condition, (b) ground condition, (c) T0 shot peened condition and (d) T1 shot peened condition; (e) combines all the data points in (a)(b)(c)(d); (f) half surface crack length $c$ at different fatigue life ratios in all conditions.

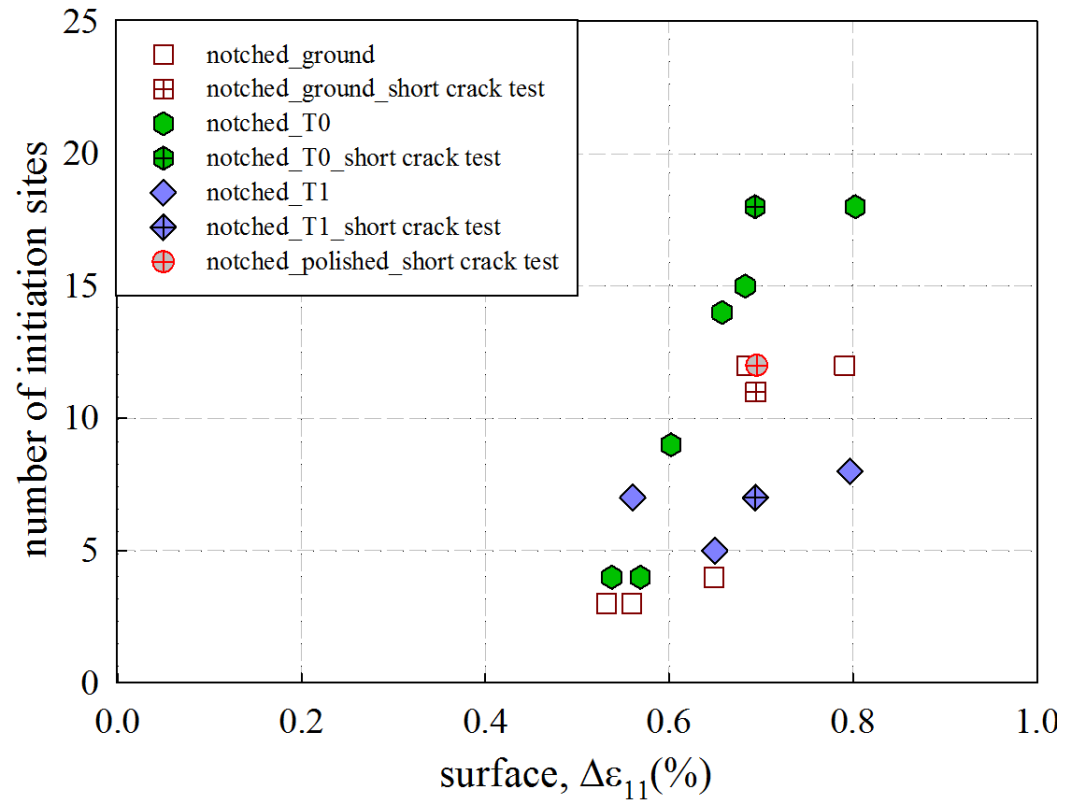

Figure 16 Comparison of crack initiation sites at various strain levels. 

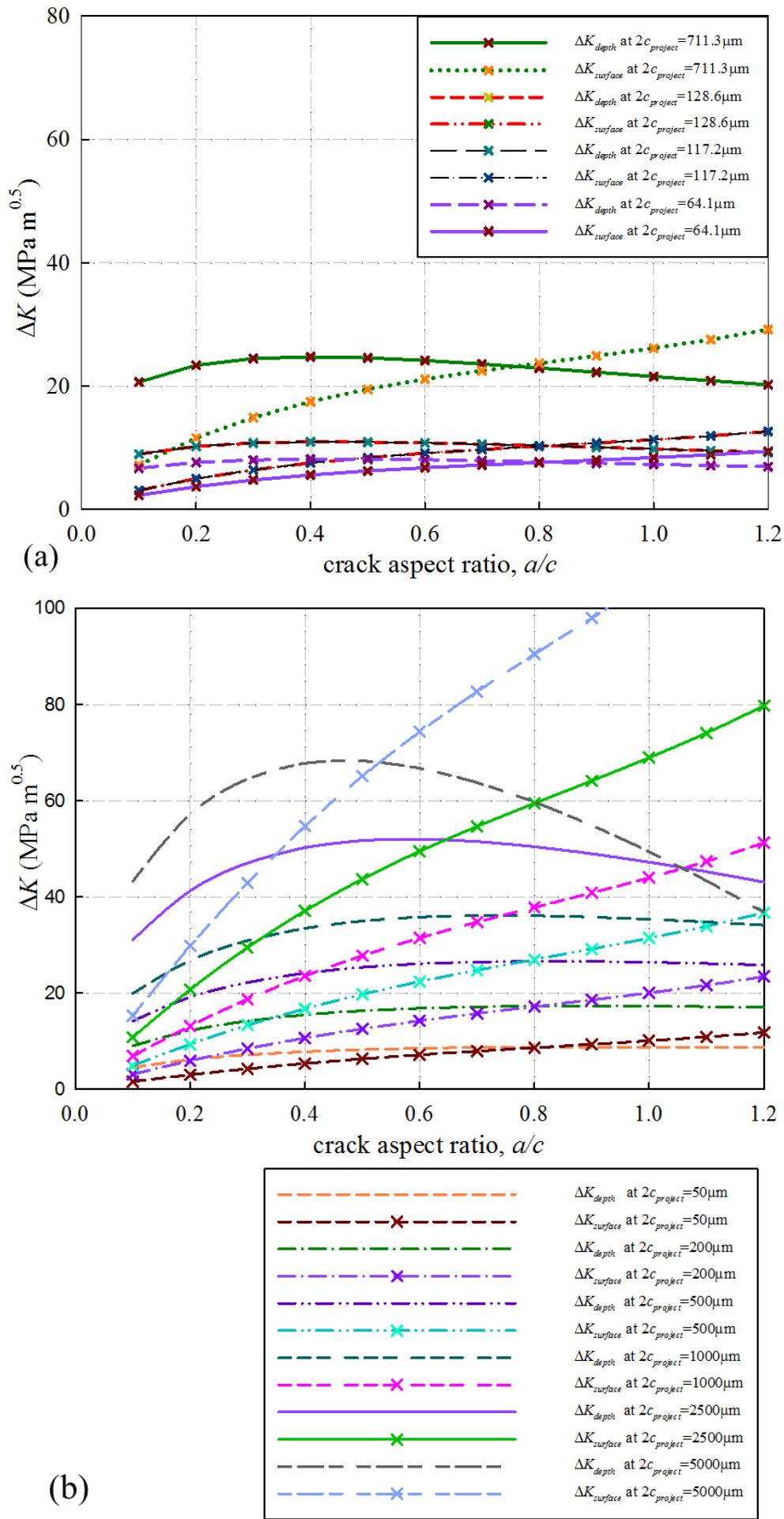

Figure 17 (a) $\Delta K$ at various $a / c$ conditions assuming fatigue area was fixed (not considering the shot peening effects); (b) $\Delta K$ at various surface crack lengths $2 c_{\text {project. }}$. 

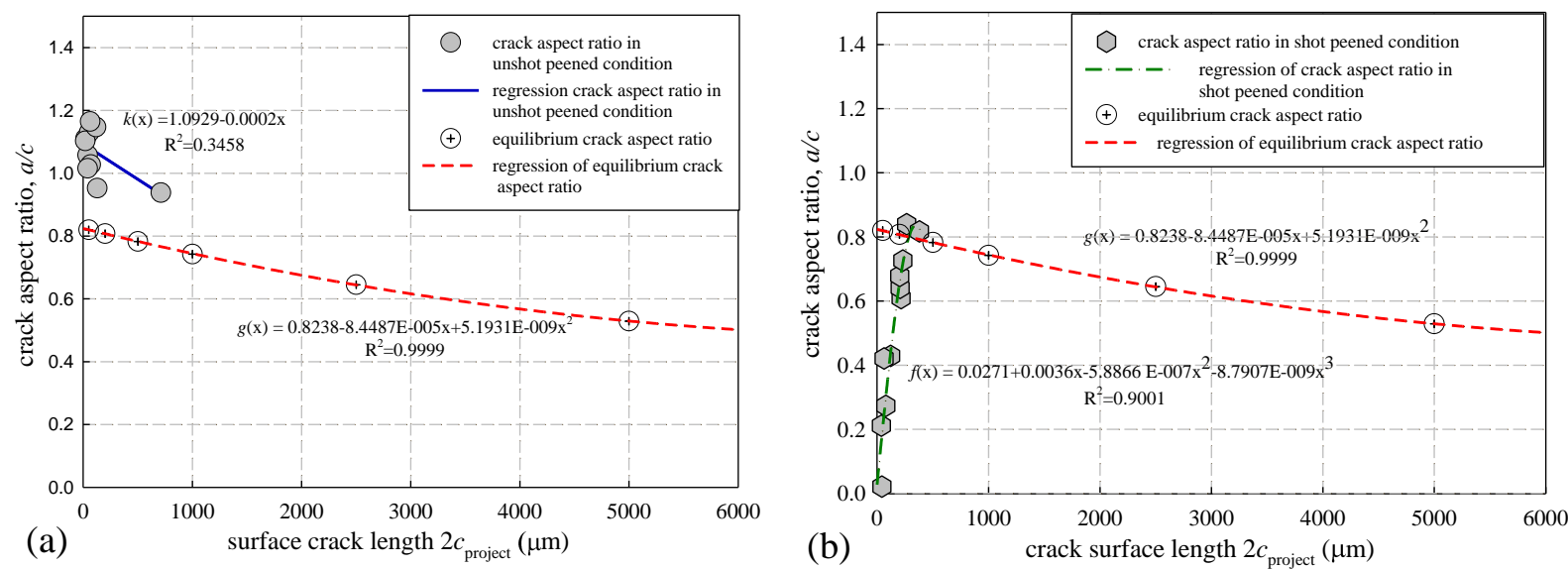

Figure $18 \mathrm{a} / \mathrm{c}$ evolution in (a) non-shot peened and (b) shot peened conditions.
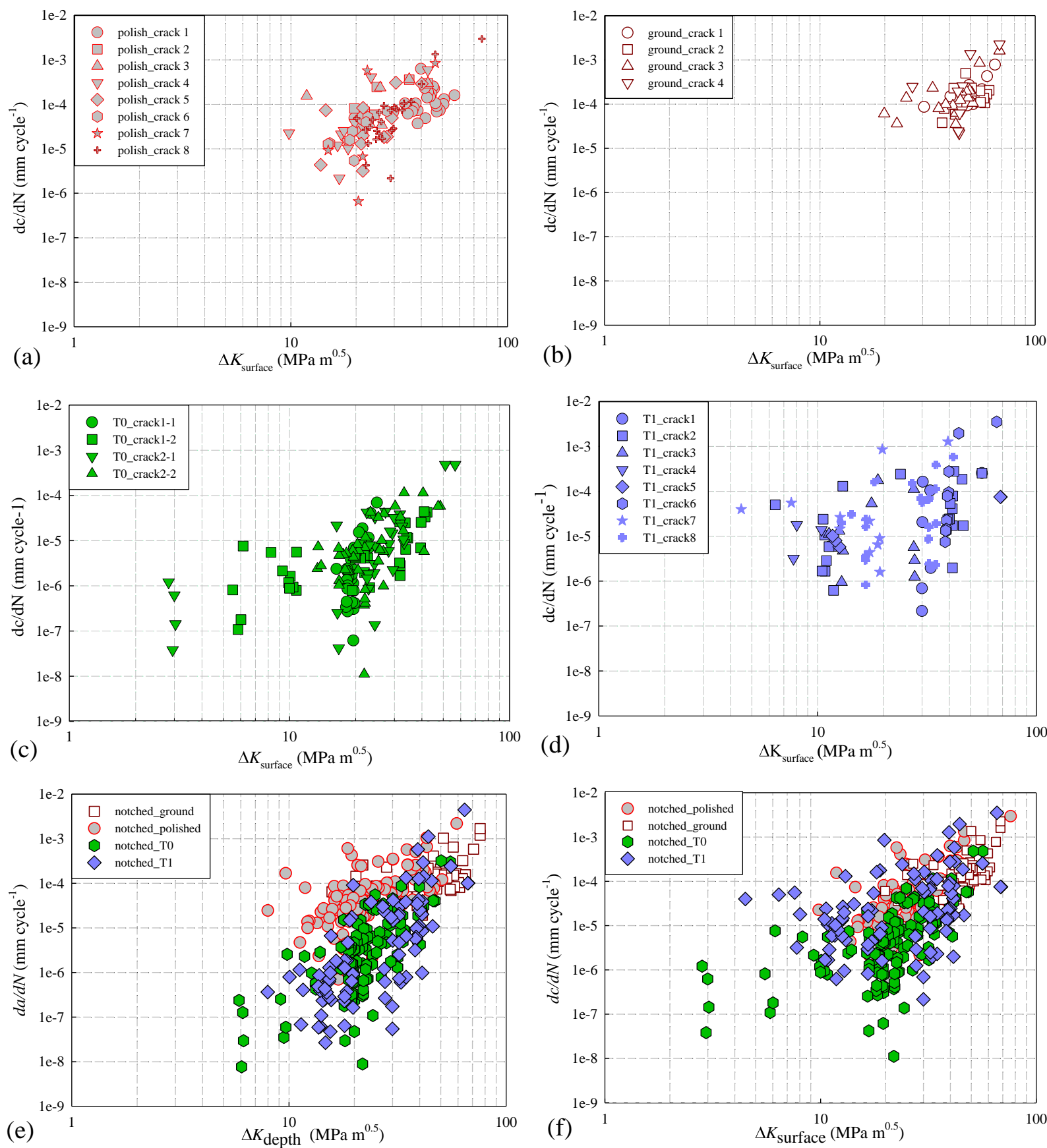
Figure 19 Crack propagation rate as a function of stress intensity factor range $\Delta K_{\text {surface }}$ (considering the evolution of crack aspect ratio a/c): dc/dN as a function of $\Delta K_{\text {surface }}$ in (a) polished surface condition, (b) ground surface condition, (c) T1 and (d) T0. To allow comparison among these conditions, (e) combines all the data points in (a)(b)(c)(d); (f) $d a / d N$ as a function of $\Delta K_{\text {depth }}$ in all conditions.
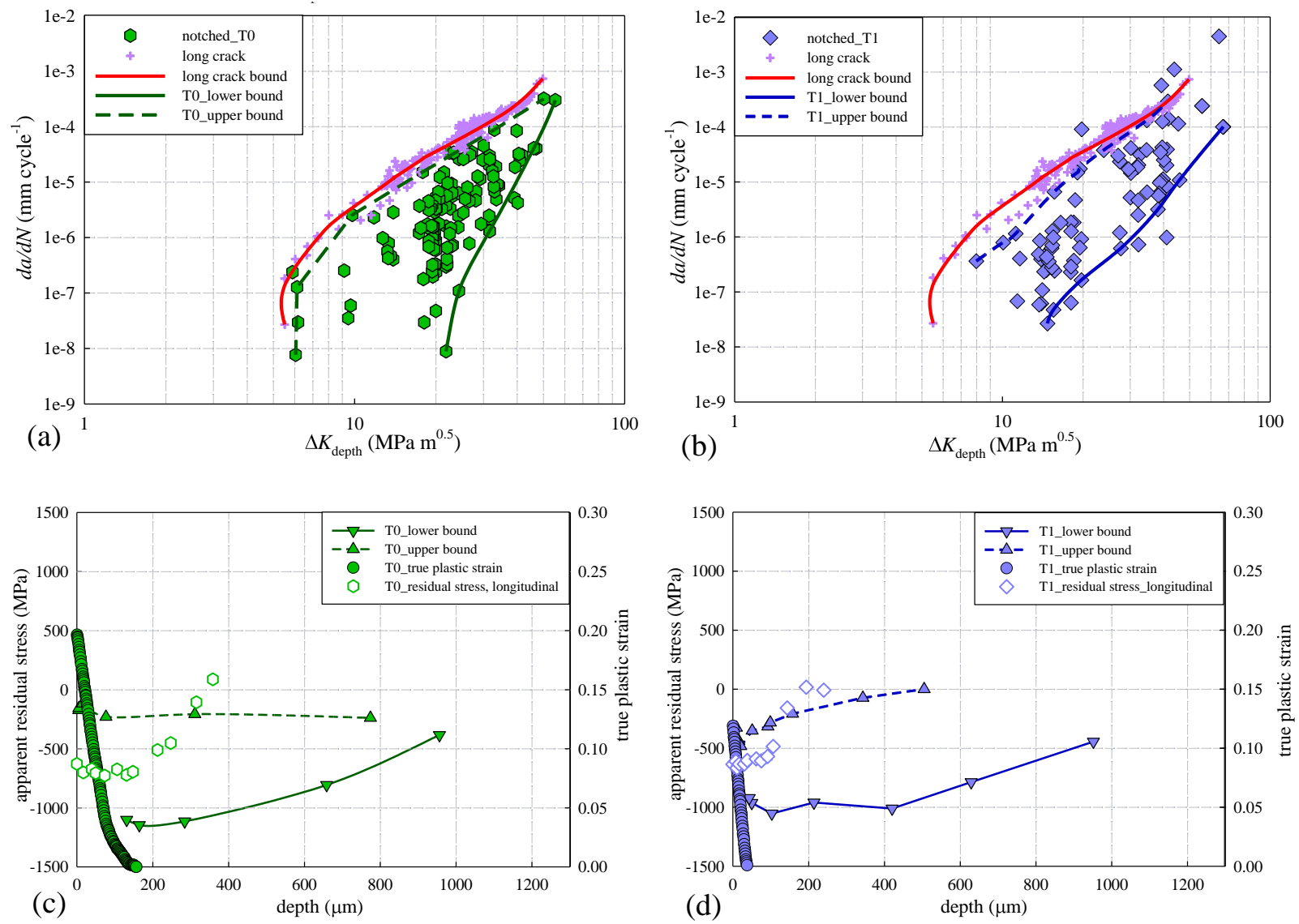

Figure 20 Comparison of fatigue crack growth rates as a function of $\Delta K$ between long crack and short cracks in: (a) T0 and (b) T1; apparent residual stress based on the equivalent crack driving force as a function of depth in : (c) T0 and (d) T1. 


\section{References}

[1] D.A. Hills, R.B. Waterhouse, B. Noble, An analysis of shot peening, The Journal of Strain Analysis for Engineering Design, 18 (1983) 95-100.

[2] V. Schulze, Modern mechanical surface treatment: states, stability,effects, Wiley, New York, 2005.

[3] H.Y. Miao, D. Demers, S. Larose, C. Perron, M. Lévesque, Experimental study of shot peening and stress peen forming, Journal of Materials Processing Technology, 210 (2010) 2089-2102.

[4] E.R. De los Rios, A. Walley, M.T. Milan, G. Hammersley, Fatigue crack initiation and propagation on shot-peened surfaces in A316 stainless steel, Int. J. Fatigue, 17 (1995) 493-499.

[5] Y.K. Gao, X.R. Wu, Experimental investigation and fatigue life prediction for 7475-T7351 aluminum alloy with and without shot peening-induced residual stresses, Acta Mater., 59 (2011) 3737-3747.

[6] J. Lindemann, C. Buque, F. Appel, Effect of shot peening on fatigue performance of a lamellar titanium aluminide alloy, Acta Mater., 54 (2006) 1155-1164.

[7] Y. Mutoh, G.H. Fair, B. Noble, R.B. Waterhouse, The effect of residual stresses induced by shotpeening on fatigue crack propagation in two high strength aluminium alloys, Fatigue \& Fracture of Engineering Materials \& Structures, 10 (1987) 261-272.

[8] I.E. Kopsov, The influence of hammer peening on fatigue in high-strength steel, Int. J. Fatigue, 13 (1991) 479-482.

[9] A.M. Eleiche, M.M. Megahed, N.M. Abd-Allah, The shot-peening effect on the HCF behavior of high-strength martensitic steels, Journal of Materials Processing Technology, 113 (2001) 502-508.

[10] L. Wagner, Effect of mechanical surface treatments on fatigue performance of titanium alloys, in: R.R. Boyer, D. Eylon, G. Lutjering (Eds.) fatigue Behaviour of Titanium Alloys, TMS, Warrendale, PA, 1999, pp. $253-265$.

[11] P. Zhang, J. Lindemann, Influence of shot peening on high cycle fatigue properties of the highstrength wrought magnesium alloy AZ80, Scripta Materialia, 52 (2005) 485-490.

[12] K. Dalaei, B. Karlsson, L.E. Svensson, Stability of shot peening induced residual stresses and their influence on fatigue lifetime, Materials Science and Engineering: A, 528 (2011) 1008-1015.

[13] K.A. Soady, Life assessment methodologies incoroporating shot peening process effects:

mechanistic consideration of residual stresses and strain hardening part 1-effect of shot peening on fatigue resistance, Materials Science and Technology, 29 (2013) 637-651.

[14] K.A. Soady, B.G. Mellor, P.A.S. Reed, Life assessment methodologies incorporating shot peening process effects: mechanistic consideration of residual stresses and strain hardening: a review. Part 2: approaches to fatigue lifing after shot peening Materials Science and Technology, 29 (2013) 652-664. [15] K.A. Soady, B.G. Mellor, J. Shackleton, A. Morris, P.A.S. Reed, The effect of shot peening on notched Low Cycle Fatigue, Materials Science and Engineering a-Structural Materials Properties Microstructure and Processing, 528 (2011) 8579-8588.

[16] K.A. Soady, B.G. Mellor, G.D. West, G. Harrison, A. Morris, P.A.S. Reed, Evaluating surface deformation and near surface strain hardening resulting from shot peening a tempered martensitic steel and application to low cycle fatigue, Int. J. Fatigue, 54 (2013) 106-117.

[17] B.Y. He, K.A. Soady, B.G. Mellor, A. Morris, P.A.S. Reed, Effects of shot peening on short crack growth rate and resulting low cycle fatigue behaviour in low pressure turbine blade material, Materials Science and Technology, 29 (2013) 788-796.

[18] K.M. Perkins, M.R. Bache, The influence of inclusions on the fatigue performance of a low pressure turbine blade steel, Int. J. Fatigue, 27 (2005) 610-616.

[19] K.M. Perkins, M.R. Bache, Corrosion fatigue of a $12 \% \mathrm{Cr}$ low pressure turbine blade steel in simulated service environments, Int. J. Fatigue, 27 (2005) 1499-1508.

[20] P.M. Scott, T.W. Thorpe, A critical review of crack tip stress intensity factors for semi-elliptic cracks, Fatigue \& Fracture of Engineering Materials \& Structures, 4 (1981) 291-309.

[21] K.J. Miller, The short crack problem, Fatigue \& Fracture of Engineering Materials \& Structures, 5 (1982) 223-232. 
[22] D. Taylor, J.F. Knott, Fatigue crack propagation behaviour of short cracks:the effetct of microstructure, Fatigue \& Fracture of Engineering Materials \& Structures, 4 (1981) 147-155.

[23] J.S.J. Hudak, Small crack behavior and the prediction of fatigue life, Journal of Engineering Materials and Technology, 103 (1981) 26-35.

[24] K.S. Ravichandran, J.M. Larsen, Effects of crack aspect ratio on the behavior of small surface cracks in fatigue: Part II. experiments on a titanium (Ti-8Al) alloy, Metallurgical and Materials Transactions A, 28 (1997) 157-169.

[25] K.S. Ravichandran, Effects of crack aspect ratio on the behavior of small surface cracks in fatigue: Part I. simulation, Metallurgical and Materials Transactions A, 28 (1997) 149-156. 